\title{
Capítulo 7 \\ factores que inciden en la perdurabilidad de una empresa familiar del sector agroindustrial*
}

\section{factors that incident the perdurability of a family com- pany in the agro-industrial sector}

\author{
Enmanuel Nava Sarmiento ${ }^{1}$ \\ Sandra Jaimes Mora ${ }^{2}$ \\ Laura Barrera Rodríguez ${ }^{3}$
}

\footnotetext{
* Proyecto: Empresas Familiares en Norte de Santander: una mirada a casos de éxito desde la perdurabilidad. Grupo de Investigación ALEF, Universidad Simón Bolívar.

1 Universidad Simón Bolívar Extensión Cúcuta. Cúcuta, Colombia. e.nava@unisimoncucuta.edu.co - https://orcid.org/0000-0003-2311-8354

2 Universidad Simón Bolívar Extensión Cúcuta. Cúcuta, Colombia. sjaimes@unisimonbolivar.edu.co - https://orcid.org/0000-0001-9363-6101

3 Universidad Simón Bolívar Extensión Cúcuta. Cúcuta, Colombia. lbarrera@unisimonbolivar.edu.co - https://orcid.org/0000-0002-6572-0469
} 


\section{Gerencia de las organizaciones.}

Un enfoque empresarial

\section{RESUMEN}

El objetivo general de esta investigación fue determinar los factores de perdurabilidad a través del estudio de caso de una empresa arrocera en Norte de Santander vinculada al sector agroindustria. Se realizó en una empresa clasificada en el ranking de las mejores empresas del Norte de Santander publicado por la Cámara de Comercio de Cúcuta en el año 2015, y así poder identificar los factores que la han llevado a perdurar por más de 5 décadas en la región, contribuyendo con la generación de empleo, indicadores de crecimiento y progreso a gran parte de la población. Se sustentó con base en referentes teóricos desde la perdurabilidad, incluye conocer una serie de factores que hace que influyan en la permanencia y sostenibilidad de las empresas. Se utilizó un enfoque cualitativo que permitió la recolección y análisis de los datos para realizar la interpretación a través de una red semántica y una revisión documental que soportó y permitió determinar factores como la gestión administrativa que llevaron a esta empresa a tener esa longevidad en el tiempo.

Palabras clave: perdurabilidad, empresa familiar, desarrollo, innovación, gestión.

\section{ABSTRACT}

The chapter presents the results of an investigation whose general objective was oriented to determine the factors of Business sustainability through the case study of a rice company of trajectory and classified in the ranking of the best companies of Norte de Santander, according to the Chamber of Commerce of Cucuta by the year 2015. This study was based on the theoretical durability. Through a qualitative methodology from inter- 
view techniques and documentary analysis, data collection and analysis were allowed to perform the interpretation through of a semantic network in which factors such as innovation capacity, administrative management, the target market, among others, have been identified that have led the company to last for more than 5 decades in the region. These, contributing to the generation of employment, indicators of growth and progress to a large part of the population.

Keywords: perdurability, family business, development, innovation.

\section{INTRODUCCIÓN}

La importancia de las empresas familiares trasciende a lo largo de los años debido al impacto generado en la economía actual del país, pues son fuentes generadoras de empleo y contribuyen al desarrollo y crecimiento productivo en el país. El trascender de generación en generación permite la permanencia activa dentro del sector económico actual; este tipo de empresas pasan gran parte del tiempo buscando estrategias para mantenerse competitivas, innovando sus procesos y haciendo énfasis en que la relación empresa-familia debe ser totalmente independiente. Este estudio constituye la fase inicial de un macroproyecto que se está desarrollando en el marco de esta temática; una de sus finalidades es conocer qué se ha hecho en materia de investigación sobre las empresas familiares, cuáles son las temáticas más trabajadas, el impacto laboral que generan en Norte de Santander, los estilos de gobernanza y cuáles son los perfiles académicos de los directivos de este tipo de empresas. 


\section{Gerencia de las organizaciones.}

Un enfoque empresarial

Las empresas de familia se han constituido como una forma empresarial que busca impulsar la economía a través del cumplimiento de su objeto social y actividad económica. A nivel mundial conforman un poco más del $70 \%$ del total de organizaciones empresariales constituidas (Martínez, 2010); muchas de estas con gran trayectoria y determinantes en la contribución a indicadores de crecimiento y desarrollo económico en su área de operación, encontrando casos exitosos como Ford, Levi Strauss, Michelin, L'Oreal, Fiat, Zara, entre otros (Gaitán, Hincapié y Castro, 2013).

En Colombia igualmente las empresas de familia representan más del 70 \% del sector real de la economía (Gaitán, Hincapié y Castro, 2013), siendo el tránsito a la segunda generación determinante para su perdurabilidad donde la mezcla de problemas familiares con el manejo de la empresa son algunas de las causas que generan crisis en ellas. Sobre el caso colombiano, recientemente Ernesto Poza (2013) declaró que las empresas de familia ocupan gran parte del mercado laboral, denotando en la última medición que esta forma de organización empresarial causa el $65 \%$ del producto interno bruto (PIB) en el país, afirmando a la vez que las empresas familiares asocian su ciclo de vida a un término de 18 años o más durante el manejo de la primera generación, perdurando tan solo el $32 \%$ para ser dirigidas por la segunda generación, y el $12 \%$ sobrevive para ser lideradas por integrantes de la tercera generación.

El departamento de Norte de Santander se encuentra en el puesto 18 según el Índice de Competitividad (IDC, 2016), en el cual, de 26 departamentos analizados en tres factores de competitividad 
con 90 variables exigentes no se encuentra muy bien posicionado en la medición, tan solo superando a departamentos como Córdoba, Chocó, Cauca y Sucre. La ciudad de Cúcuta se conoce como el primer centro informal del país con el 69,8 \%, comprometiendo y afectando de esta manera la productividad y competitividad de la región según el DANE 2016, la cual hace ver que la región necesita de empresas duraderas, productivas y comprometidas con el progreso, no solo de sus familias, sino también del contexto donde operan y llevan a cabo su objeto social.

El mismo Departamento para el año 2015 contribuyó con 1,6\% en el PIB nacional (DANE, 2005) cifra muy baja si se toma en cuenta y se contrasta con departamentos hermanos como Santander, el cual contribuyó con números cercano al 8 \%. Cifra insuficiente y lamentable para una región con historia y trascendencia en la creación del país, demostrando que lo que hace falta a la región es empresas que perduren a través del tiempo, y así evitar consecuencias de su ausencia tales como ser calificados por ser la ciudad con más alta tasa de informalidad, ocupando con desconcierto el primer puesto en el país con el 68,8 \% a septiembre de 2016 según el DANE, manteniendo esa posición por muchos años, dando efecto el categorizarse como una de las principales ciudades con alto índice de desempleo. A todo esto se suma la cultura de la zona en cuanto al tema del contrabando que afecta a las pocas empresas que hay; seguido de las prácticas indebidas como la evasión de impuestos, entre otros aspectos negativos.

De acuerdo con el artículo 'Trampas Familiares, sus efectos negativos y cómo afrontarlos', "las malas prácticas empresariales, conocidas como trampas familiares, resultaron ser las mayores 


\section{Gerencia de las organizaciones.}

Un enfoque empresarial

causas de la alta mortandad de estas compañías" (Gómez Betancur, 2013). Es esta una de las causas en las que recaen las empresas de este tipo, al no diferenciar los roles que cada colaborador sanguíneo tiene al aportar a su compañía, queriendo hacer de todo y cada uno pretendiendo dirigir la organización.

Por otro lado, la región se ha detenido en el ámbito empresarial, debido a su dependencia comercial con Venezuela; nunca se preocupó por desarrollar y fortalecer la industria y que las empresas se mantuvieran autosostenibles, perdurables y con una economía diversificada. En contraste a las cifras arrojadas por el DANE, y en un intento por salvar y recuperar la economía de la zona en un progreso continuo, el Plan Regional de Competitividad de Norte de Santander proyectó como visión: "Norte de Santander en el año 2021 es el primer departamento fronterizo reco-

210 nocido a nivel nacional e internacional como el principal centro de negocios y logística de la región andina, por su desarrollo industrial, competitivo en carbones y cerámica, productos forestales, madera y muebles, confecciones y calzado, agroindustria y servicios a la producción, el bienestar y el entretenimiento con un modelo de desarrollo económico endógeno, autoeficiente y autosostenible, cuyos principios rectores son el emprendimiento y la asociatividad".

Asimismo, "con un modelo de desarrollo económico endógeno, autosuficiente y auto-sostenible, cuyos principios rectores son el emprendimiento y la asociatividad" (p.6). El 70 \% de las empresas inician como emprendimiento familiar que buscan impulsar la economía. De acuerdo a Martínez (2010) se pretendió de esta forma contribuir con este objetivo en el desarrollo y cumplimiento de la visión departamental con el aporte de este estudio 
para la región y sus factores claves que han permitido a la empresa objeto de estudio perdurar en el tiempo.

\section{ESTADO DEL ARTE Y FUNDAMENTACIÓN TEÓRICA}

Teóricamente la perdurabilidad empresarial ha sido abordada como objeto de estudio. Sallenave (citado en Flint, 1999) destaca que el producto, el mercado, el capital y el personal, son factores que deben potencializarse positivamente para la sostenibilidad de las organizaciones, aspectos que junto con otros, son propuestos también por Restrepo et al (2009), quienes sostienen que la perdurabilidad es el resultado de factores como el sostenimiento en el tiempo, los resultados financieros, la rotación del personal, el sentido de pertenencia de los empleados, la eficacia y eficiencia operativa, la gestión administrativa, la flexibilidad ante la variación del entorno sectorial en que opere la organización, y la respuesta de esta a los cambios de las fuerzas del mercado.

Por su parte, Daft (2011) sugiere que hay cuatro etapas fundamentales que describen el desarrollo de una organización. Tales etapas son las siguientes: emprendedora, colectividad, formalización y elaboración. De acuerdo con esta referencia, en la etapa emprendedora, "cuando una organización nace, el énfasis es en la creación de un producto o servicio y en sobrevivir en el mercado" (p.340). En esta etapa sus fundadores o dueños colocan su mejor empeño y las jornadas de trabajo son extensas para que la empresa se mantenga en marcha por sí misma; de esta manera surge la crisis de necesidad de liderazgo. Durante la etapa de colectividad, "si el liderazgo en situaciones de crisis es resuelto, se obtiene un poderoso liderazgo y la organización empieza a 


\section{Gerencia de las organizaciones.}

Un enfoque empresarial

desarrollar metas y una dirección clara" (p.341). Si se logra superar la crisis de liderazgo para continuar con el crecimiento y mantener un equilibrio estable, se crea el nuevo reto de delegar responsabilidades y hacer parte de la misión y objetivos a los colaboradores, sintiendo como propia la organización y logrando un crecimiento en cada uno de los miembros. En este sentido, García et al (2017) y Bracho et al (2012) acotan cómo un buen liderazgo propende al empoderamientos de los colaboradores y al alcance de metas.

La siguiente, es "La etapa de formalización [que] implica el establecimiento y la utilización de reglas, procedimientos y sistemas de control" (p.342). Es allí donde los altos directivos empiezan a crear la planeación y estrategias, el crecimiento se torna lento y se da el comienzo de la burocracia, se incorporan nuevos estilos de motivación, incentivos y recompensas para asegurar un mejor rendimiento laboral. Por último, se puede afirmar que "En la etapa de elaboración, a nivel de toda la organización, los gerentes desarrollan capacidades para enfrentarse a los problemas y trabajar juntos" (p.342). Frecuentemente, como consecuencia de ello, la organización puede volverse totalmente burocrática y, por ello, debe pensar en renovar e innovar sus procesos para que la compañía permanezca con vida en el entorno laboral.

De acuerdo con el Manual de Innovación para pymes (2013) la innovación se define como la aplicación comercial de una idea de forma que se originen productos, procesos o servicios nuevos o mejorados, permitiendo generar beneficios empresariales, lo que significa para los clientes mejores productos en cuanto a términos de calidad y precios para satisfacer sus necesidades, 
obteniendo la organización mejores resultados para dar respuesta a las amenazas y competencia que se pueda presentar en el entorno empresarial, lo que genera un crecimiento sostenible y a su vez un incremento en la generación de nuevas oportunidades laborales para obtener la competitividad empresarial.

En este orden de ideas, Prieto et al. (2014), Cuentas y García (2016) y García et al. (2017) señalan que la competitividad de una empresa se sustenta en procesos permanentes de innovación, bajo un liderazgo estratégico que se gestione en el talento humno y los procesos administrativos.

Se puede mencionar el concepto del proceso administrativo, considerado por las organizaciones como una herramienta necesaria para conseguir el logro de los objetivos establecidos por la organización utilizando todos los recursos disponibles en ella como humanos, técnicos, económicos y tecnológicos, entre otros. El proceso administrativo consta de cuatro fases secuenciales denominadas planeación, organización, dirección y control. La Planeación es definida por Chiavenato (2002) como "la fase en la cual se pretende establecer las actividades futuras y cómo ejecutarlas con miras a satisfacer los objetivos de la empresa" (p.17). Adicionalmente, el citado autor establece que "Durante la fase de organización se identifican los medios y recursos (humanos, técnicos y económicos) necesarios para llevar a cabo la planeación" (p.17). También en Chiavenato (2002) se menciona que "La fase de dirección representa la puesta en marcha de lo que fue planeado y organizado y considera la motivación a los empleados para alcanzar los objetivos organizacionales" (p.18). Finalmente, Chiavenato (2002) indica que "La fase de control representa el 


\section{Gerencia de las organizaciones.}

Un enfoque empresarial

acompañamiento, monitoreo y evaluación del desempeño organizacional para verificar si las tareas se ejecutan de acuerdo con lo planeado, organizado y dirigido" (p.18).

De manera complementaria se aborda la investigación de mercados (marketing investigation), la cual, en la actualidad, es considerada como una herramienta administrativa y valiosa que permite recopilar, organizar y procesar la información para brindar apoyo y facilidad en la toma de decisiones, identificando (a partir de los resultados) expectativas y necesidades de los clientes, pasando de un enfoque subjetivo a un enfoque objetivo obteniendo datos reales, convirtiéndolos en ventajas competitivas frente la competencia. Kotler (2006) define la investigación de mercado como "el diseño, la recopilación, el análisis y el estudio sistemático de la información y de los datos relevantes del

214 mercado para una situación específica a la que se enfrenta la empresa" (p.106).

Lo mencionado anteriormente conlleva a la competitividad de una empresa, la cual requiere la adecuación de su estructura y mejoramiento de estrategias con el fin de obtener crecimiento y diversificación al aprovechar y combinar, exitosamente, los recursos con los que se cuenta, ofreciendo mejor servicio para obtener resultados satisfactorios considerando estrategias genéricas como las propuestas por Porter (2009), identificadas como liderazgo global en costos, diferenciación y enfoque o concentración. Respecto a la primera estrategia, el autor mencionado afirma que "El liderazgo en costos exige la construcción agresiva de instalaciones de escala eficiente, la búsqueda vigorosa de reducción de costos a partir de la experiencia, un control riguroso de gastos variables y fijos" (p.52). Esto indica que si la empresa 
quiere ser competitiva en el mercado debe manejar costos inferiores a los de sus competidores manteniendo la calidad en sus productos y servicios ofrecidos a través de factores como economías a escala, experiencia en la industria, manejo e innovación en herramientas tecnológicas, capacidad de reducir costos a medida que la producción aumente. Esta estrategia exige tener conocimiento sobre la herramienta estratégica denominada cadena de valor para identificar aquellas fuentes de ventaja competitiva en las cuales se pueden alcanzar ventajas en costos.

Según Porter (2009), "La estrategia de diferenciación brinda protección en contra de la rivalidad porque los clientes son leales a la marca y porque disminuye la sensibilidad al precio" (p.54). Debido a que se corre el riesgo de que estos cambios no sean valorados por los consumidores, antes de realizar estos cambios al momento de justificar su precio elevado, se debe realizar un estudio de las necesidades y preferencias de los compradores para determinar si es viable o no incorporar nuevos cambios que lo haga diferente a la competencia.

Haciendo referencia a la tercera estrategia, Porter (2009) afirma que "el enfoque se centra en un grupo de compradores, en un segmento de la línea de productos o en un mercado geográfico" (p.55). Esta estrategia se utiliza con el fin de ajustar las estrategias para dar respuestas a las necesidades del grupo de clientes seleccionados y lograr una mayor ventaja competitiva. Cabe destacar que las empresas que tienen un alto índice de competitividad logran un porcentaje superior en cuanto a la participación del mercado donde se conoce qué tan posicionada está la organización en relación a los competidores. Además, permite estar al tanto de si la empresa está creciendo o declinando, y de esta 


\section{Gerencia de las organizaciones.}

Un enfoque empresarial

forma crear y ejecutar acciones estratégicas para alcanzar una mayor proporción de participación en el mercado.

\section{MÉTODO}

Para el alcance de los objetivos, el estudio requirió identificar cuáles han sido los factores de perdurabilidad de las empresas familiares que conforman el aparato productivo en Norte de Santander, abordándolo desde un enfoque cualitativo, el cual permite realizar descripciones sobre la manera como el mundo es conocido y pensado por los miembros de un grupo, sobre los impulsos, deseos y motivaciones de las personas, es decir lo cualitativo explora el contexto estudiado para lograr las descripciones más detalladas y completas posibles de la situación, con el fin de explicar la realidad subjetiva que subyace a la acción de los miembros de la sociedad (Bonilla y Rodríguez, 1997, p.76).

De igual forma, Hernández, y Fernández y Baptista (2014, p.7) manifiestan que sirve para "utilizar la recolección y análisis de los datos para afinar las preguntas de investigación o revelar nuevas interrogantes en el proceso de interpretación" con un alcance descriptivo. Los mismos autores (2014, p.92) indican que "busca especificar propiedades y características importantes de cualquier fenómeno que se analice. Describe tendencias de un grupo o población" buscando conocer las historias de vida de las empresas familiares en el departamento de Norte de Santander vinculadas al sector industrial, comercial y de servicios que han pasado de generación en generación.

Lo que se pretende con este proyecto es obtener detalladamente datos cualitativos, "evidencia o información simbólica verbal, audiovisual o en forma de texto e imágenes", Hernández et al. (2014, p.9) aplicadas directamente a los directores ejecutivos 
(CEO) de cada organización de la región nortesantandereana, que lleve a conocer los factores que inciden en la perdurabilidad de dichas empresas familiares. El proyecto se llevó a cabo bajo la concepción de un diseño narrativo, los referidos autores (2014, p.487) comentan que "Pretenden entender la sucesión de hechos, situaciones, fenómenos, procesos y eventos donde se involucran pensamientos, sentimientos, emociones e interacciones, a través de las vivencias contadas por quienes lo experimentaron".

De esta manera se aplica el estudio de caso, como lo recomienda Stake (1999), quien manifiesta; "nos encontraremos con una cuestión que se debe investigar, una situación paradójica, una necesidad de comprensión general, y consideraremos que podemos entender la cuestión mediante el estudio de un caso particular" (p.16), llevando al rastreo de la empresa con la que se iba a realizar el estudio de caso tomando como criterio de inclusión aquellas que en los últimos dos años hayan sido reconocidas a nivel regional por el Observatorio Económico de la Cámara de Comercio de Cúcuta a través del ranking que este publica desde el año 2015 frente a las 100 empresas más importantes del Norte de Santander.

Como instrumento y técnica se utilizó una entrevista semiestructurada que - según Hurtado (2010, p.863) - consiste en "una especie de interrogatorio en el cual se formulan las preguntas manteniendo siempre el mismo orden y con los mismos términos, se basa en un formulario normalizado cuyas preguntas han sido previamente preparadas" con el cual se construyó el guion que se aplicó al propietario y directivo de la empresa objeto de estudio. Se construyó una matriz de categorización de variables para construir el guion como se observa en la Figura 1. 
Gerencia de las organizaciones.

Un enfoque empresarial

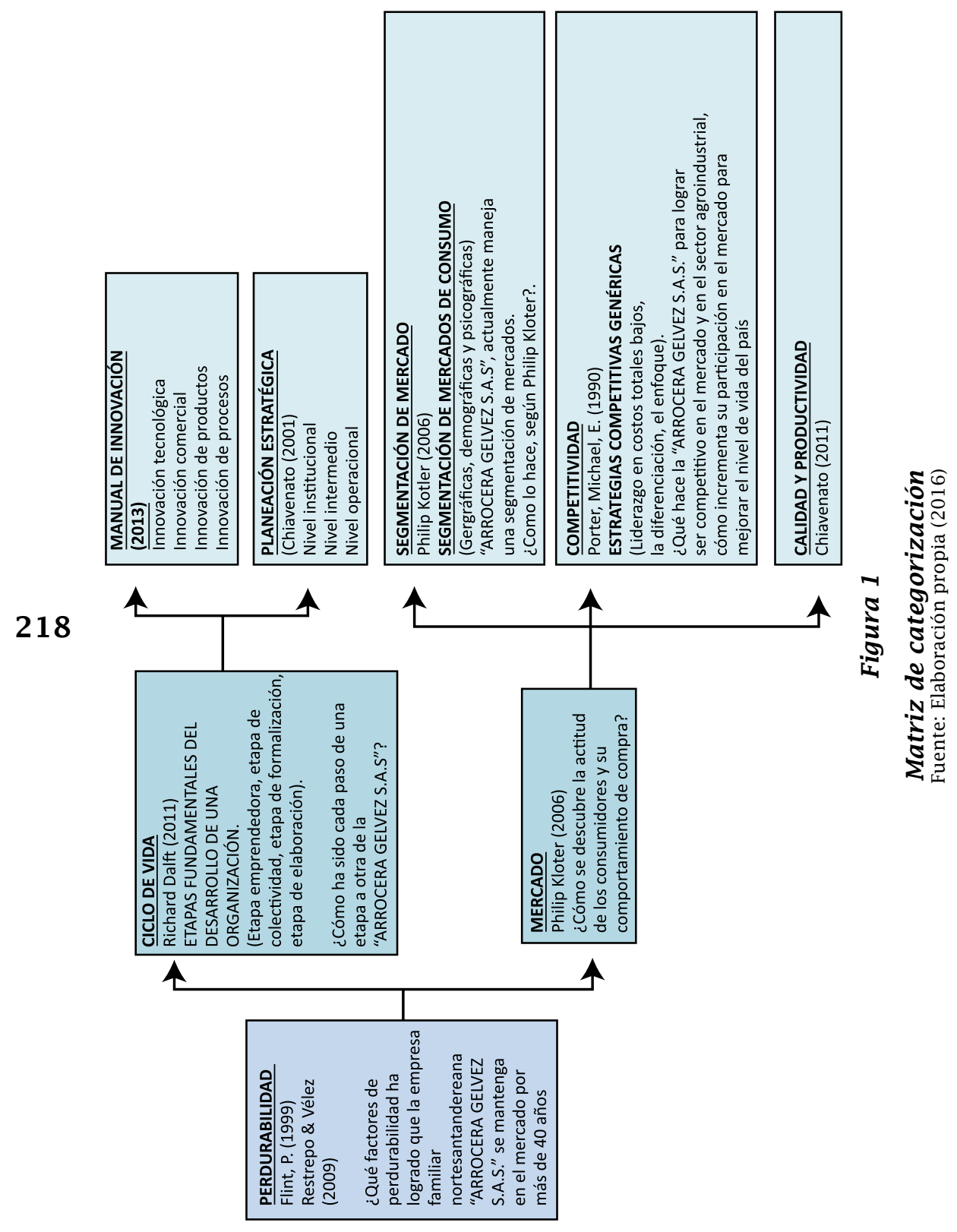


De igual forma se realizó un análisis documental con base en los datos que publica el observatorio de la Cámara de Comercio de Cúcuta, en el que muestra cifras y resultados de competitividad de la organización. Este análisis cobra sentido para la investigación, ya que según Hurtado (2010) "la información requerida para dar respuesta a la pregunta de investigación ya fue recolectada por otras personas y se encuentra consignada en archivos, registros o cualquier otro tipo de documento" (p.51), siendo este un tipo de documento institucional con el cual se buscó una comparación y soporte con la información recolectada en la entrevista realizada al directivo y dueño de la organización de la empresa de estudio, que ha sido exitosa en la región y por ende perdurable en el tiempo.

La información se procesó a través del esquema de categorización con el uso del software ATLAS.ti 7.0 versión libre, en el que se identificaron categorías propuestas y relacionadas con el marco teórico, se establecieron relaciones entre las categorías en el proceso de triangulación y se generaron redes semánticas, se hizo un análisis categorial, ya que según Strauss y Corbin (2002), el método comparativo constante es arte y ciencia, lo cual se manifiesta en "la capacidad de los investigadores de dominar categorías con buen tino, formular preguntas estimulantes, hacer comparaciones y extraer un esquema innovador, integrado y realista de conjuntos de datos brutos desorganizados" (p.14). Con base en la categorización teórica se buscó determinar de forma deductiva las que la organización ha aplicado y cuáles otras categorías emergían como inductivas llevadas a cabo en el direccionamiento estratégico. 
Gerencia de las organizaciones.

Un enfoque empresarial

\section{RESULTADOS, DISCUSIÓN Y CONCLUSIÓN}

Factores de emprendimiento e historia empresarial de Arrocera Gélvez S.A.S

Arrocera Gélvez S.A.S, empresa nortesantandereana que procesa, empaca y comercializa como producto principal el arroz y hoy en día algunos derivados, fue fundada en la década de los sesenta por el señor don Teódulo Gélvez Albarracín.

En la ciudad de San José de Cúcuta, específicamente en el año de 1966, una pareja de esposos junto a sus hijos, de ocupación comerciantes de productos de la canasta familiar (arroz, panela, harina, etc.), desde el ejercicio multifuncional como propietarios de una tienda de abarrotes en el antiguo mercado La Sexta, detectan la necesidad de ampliar su negocio y reconoce que es el arroz el que más se vendía. Esto se encaminó a incursionar más a

220 fondo en el sector agroindustrial en la zona fronteriza, considerada la más dinámica del país por la variedad de productos que se pueden comercializar alrededor de la región.

El inicio lo marca la adquisición de un molino artesanal, limitado, pero que en su época aportó como toda aquella herramienta que tiene la capacidad de optimizar los procesos, a conseguir el logro y el cumplimiento de los objetivos institucionales del entonces y a poseer la capacidad de apoyar a cultivadores de la región. Al paso de los años, nuevos avances y el incremento del consumo de su producto principal, el arroz, empieza a generar beneficios no solo para la empresa de la familia Gélvez, sino también nuevos empleos para la región. Primeramente funcionó bajo la figura legal de constitución de la empresa como Sociedad Limitada (1978), y que 23 años más tarde, es decir en el año 2001, cambia a ser sociedad por acciones simplificada S.A.S. 
El actual presidente de la junta directiva Javier Gélvez, sucesor en primer grado de consanguinidad del fundador, don Teódulo Gélvez Albarracín, asume el cargo directivo en el año 87 de forma inesperada y poco planeada: se enfoca, en primera instancia, en la definición de la figura jerárquica, el diseño y socialización de la unidad de mando, la estipulación de funciones, delegaciones, toma de decisiones; es decir, el diseño e implementación del protocolo familiar, que en pocas palabras hace referencia a las condiciones, normas, políticas que se deben cumplir a cabalidad y sin excepciones; la equidad entre sus colaboradores es primordial. La razón de ser de la arrocera Gélvez está apoyada en la ejecución de labores en conjunto o trabajo de equipo, talento humano competente y también de la tecnología con el objeto de lograr ser reconocidos en el 2020 como la más prestigiosa y posicionada empresa del sector agroindustrial del norte al oriente del país. Trabajo continuo, "gente que trabajaba de domingo a domingo desde las 3 de la mañana", es decir, dedicación, compromiso y responsabilidad con lo que se hace, definen su permanencia alrededor de 50 años en el mercado.

\section{Relación de las categorías con los factores de perdurabilidad identificados en Arrocera Gélvez S.A.S.}

En el análisis realizado con la sistematización de la entrevista en el software de Atlas. ti 7, permitió establecer los siguientes resultados. En este sentido, la Figura 2 presenta la red semántica correspondiente a la categoría innovación. 
Gerencia de las organizaciones.

Un enfoque empresarial

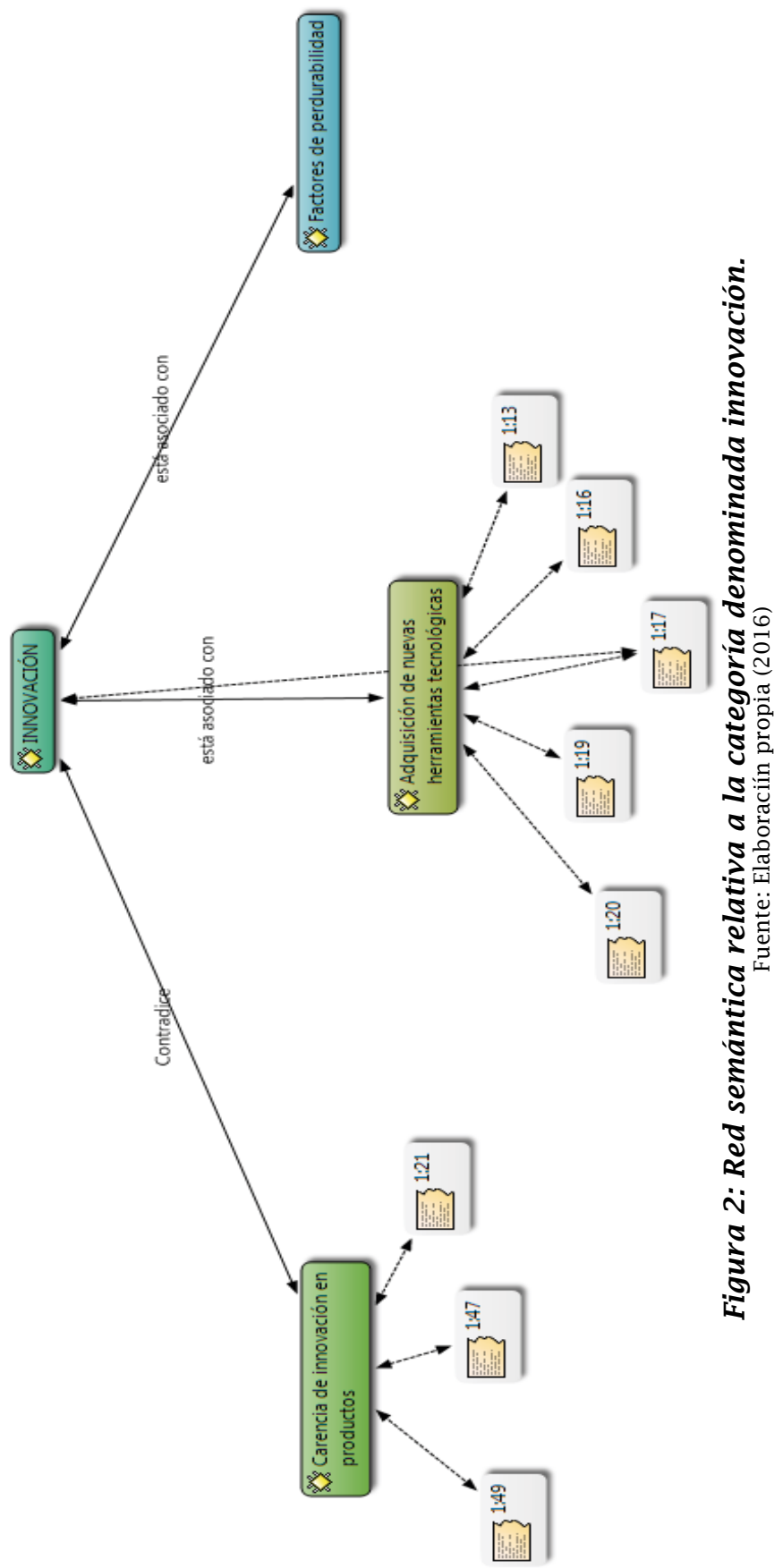


En la categoría de innovación, tanto tecnológica como comercial, de productos y de procesos se logra visualizar, en una de las categorías deductivas denominada adquisición de nuevas herramientas tecnológicas, que la arrocera Gélvez cuenta con alta tecnología. Esto le ha permitido a la empresa agilizar los diversos procesos de producción y empaque, lo cual permite generar productos que cumplen con los estándares de calidad establecidos, $\mathrm{y}$ acordes con las exigentes necesidades y requerimientos del mercado actual.

Así mismo se determina que existen debilidades en la arrocera Gélvez como la carencia de innovación en productos, puesto que la empresa no está enfocada en lanzar nuevos productos al mercado, ni mejorar los existentes, y adicionalmente no están dispuestos a realizar estudios de mercado para detectar nuevas necesidades; solo se basan en lo que hace la competencia en la que son destacados como líderes, arroz Diana y arroz Roa, según los datos recolectados por la fuente de información. Javier Gélvez, quien es actualmente el CEO de la compañía, afirma que la perdurabilidad en el tiempo no solo de la arrocera Gélvez sino también de sus otras propiedades como son: Hotel Casa Blanca y la ladrillera Casablanca, se debe a la presencia de ciertos factores de perdurabilidad, entre los cuales se pueden mencionar: Ser responsable, asumir las consecuencias de sus errores, y el compromiso tanto con los agricultores (quienes son los que proveen la materia prima) como con sus clientes y consumidores finales.

Por otra parte, en la Figura 3 se muestra la red vinculada con la categoría identificada como gestión administrativa. 
Gerencia de las organizaciones.

Un enfoque empresarial

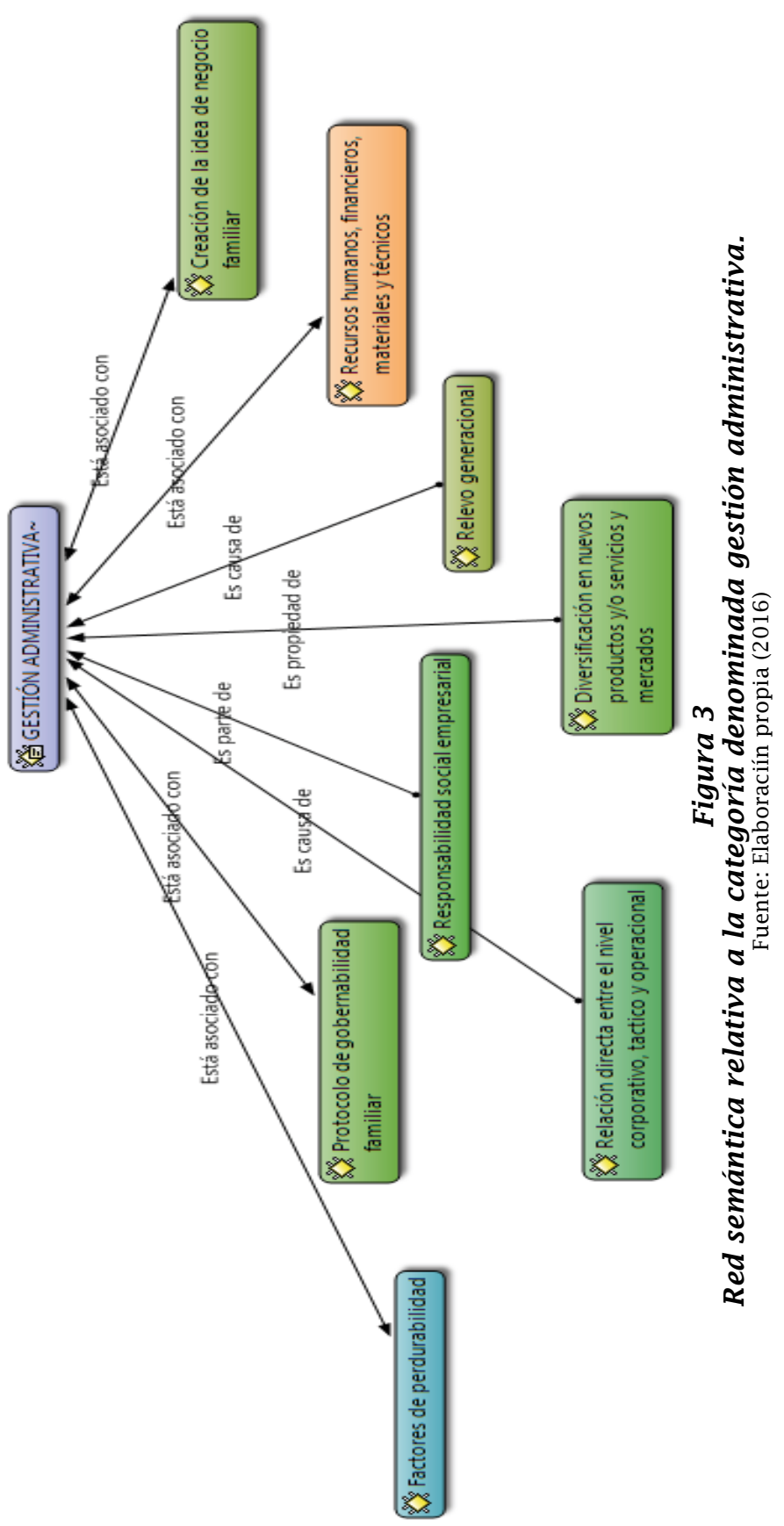


Categoría inductiva denominada Creación de la idea de negocio familiar. Se analiza cómo ha sido la constitución de la empresa desde sus inicios en la década de los años 60, cuando el fundador, Teódulo Gélvez Albarracín, empezó con el negocio como una tienda de abarrotes en el mercado de la sexta de la ciudad de Cúcuta. Según el señor Teódulo Gélvez Albarracín se identificó la necesidad de poner en marcha este tipo de negocio, ya que el arroz era un producto demandado en gran cantidad por los cucuteños y localidades vecinas a su ubicación. En el año 1987, la muerte del fundador conlleva inmediatamente a otra de las categorías inductivas que se denomina Relevo generacional; es decir, la aparición de la segunda generación a cargo de la empresa.

Mediante la gestión administrativa se logró analizar la planeación estratégica de la arrocera Gélvez S.A.S.; la rienda de la empresa es asumida por su esposa e hijos, y luego de común acuerdo familiar es administrada y dirigida por uno de sus hijos Javier Gélvez, quien fue la fuente de información primaria para obtener dichos datos. El nuevo director, desde su conocimiento empírico, impuso un nuevo diseño e implementó un protocolo de gobernabilidad familiar, de donde se destacan otras categorías inductivas como: la creación de nuevas políticas, la conformación de la junta directiva liderada por la familia Gélvez y asesorada por terceros. En este escenario, se hace indispensable y altamente recurrente la categoría inductiva de los recursos humanos, financieros, materiales y técnicos: como son el personal contratado, la materia prima e insumos, al igual que la maquinaria y equipo para el cumplimiento de los objetivos estratégicos de la arrocera Gélvez. La fuerte presencia del actual director en el presente trabajo, destaca su importancia para el desarrollo y ejecución de estrategias. 
Gerencia de las organizaciones.

Un enfoque empresarial

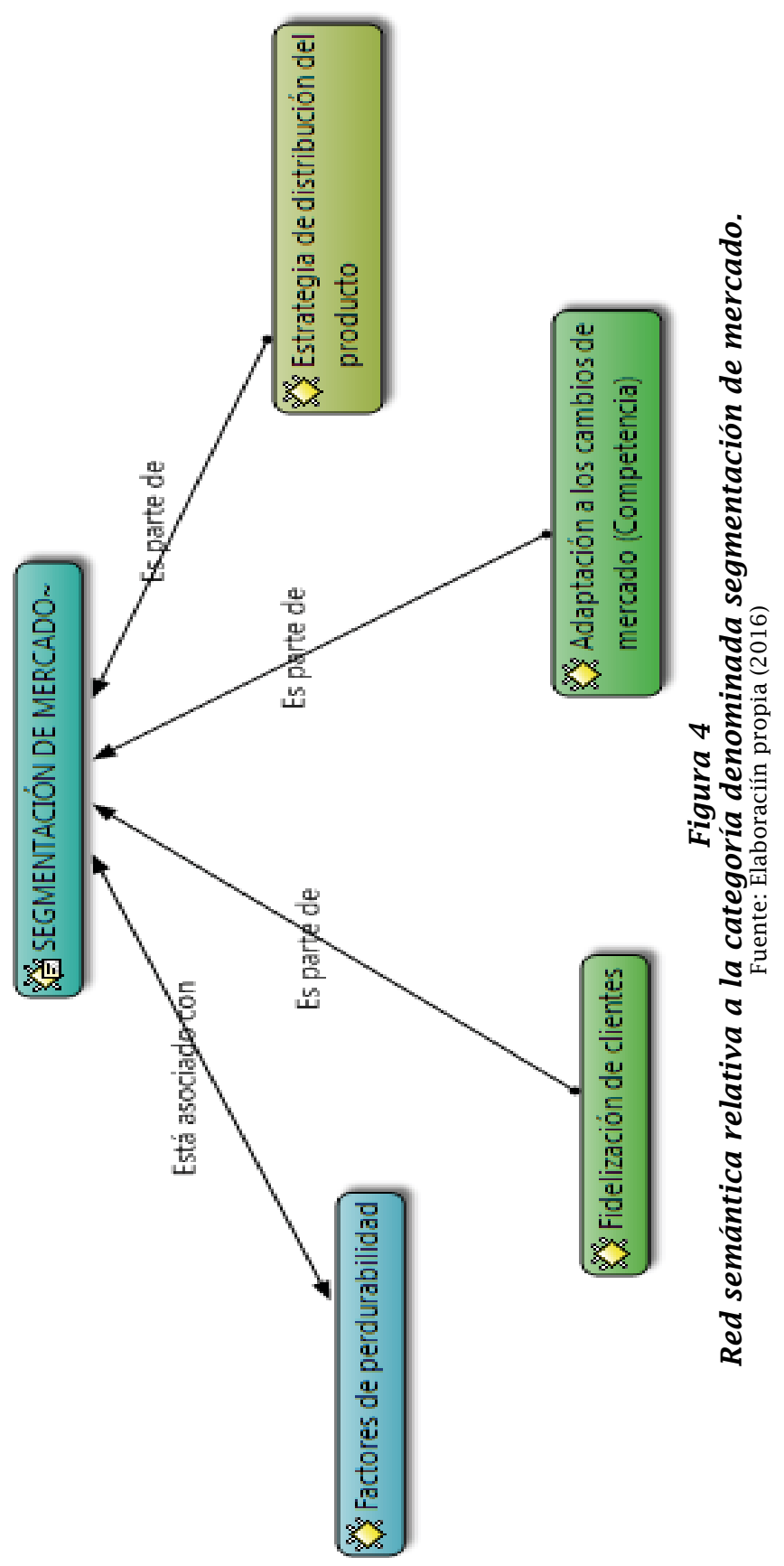


Continuando con el análisis de los resultados obtenidos, mediante la Figura 4 se bosqueja otra categoría importante denominada Segmentación de mercado.

El análisis de la segmentación de mercado permitió detectar que no existe ningún mercado objetivo, ya que sus productos son ofrecidos a cualquier estrato y distribuido en la zona de los Santanderes y la Costa, lo que tiene que ver con los departamentos del Cesar, Magdalena, Bolívar, Atlántico y La Guajira, que son el mercado natural que siempre se ha tenido para comercializar sus productos, contando con diferentes canales de distribución, considerados como las bodegas a nivel local, supermercados y mayoristas, donde se debe estar muy pendiente de la variación constante del mercado para comercializar los productos que ofrece arrocera Gélvez, el cual cuenta con tres líneas, denominados como el principal y el más vendido arroz Gélvez; también existen otras dos líneas económicas con arroz Don Teo y arroz Kogui.

Otra de las estrategias, consideradas como deductivas, es la adaptación al mercado, lo cual implica que se debe tomar en cuenta la rivalidad inter-empresas. En este sentido, se debe observar qué hace la competencia para poderlo aplicar en la arrocera Gélvez, sin necesidad de emplear técnicas de plan de mercadeo o de hacer inversiones, lo cual implica gastos y puede generar utilidades mínimas (benchmarking). Otro de los aspectos más relevantes en la segmentación de mercado, se puede considerar la categoría deductiva de la Fidelidad con el cliente la cual viene condicionada por la capacidad de respuesta que se le dé al cliente. Si siempre se cumple con lo pactado, usualmente, se logra fidelizarlos. 
Gerencia de las organizaciones.

Un enfoque empresarial

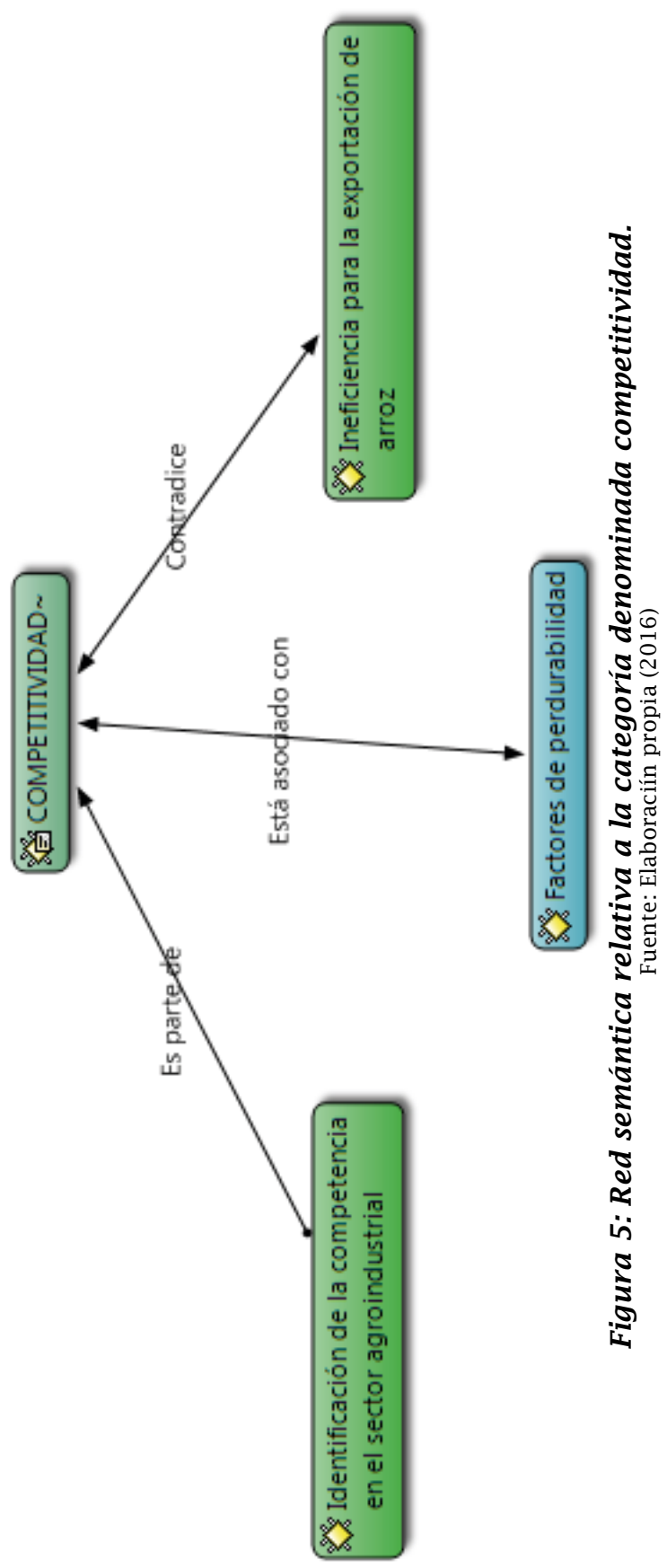


En cuanto a la categoría de Competitividad, como se puede ver en la Figura 5, es poco recurrente en la entrevista aplicada, es decir, la empresa no considera la competitividad como un factor relevante.

Lo anterior trae como consecuencia la exaltación de la categoría deductiva denominada Ineficiencia la cual se pone de manifiesto durante el proceso de exportación de arroz. El director de la empresa justifica tal ineficiencia argumentando que Colombia es un país ineficiente para exportar este producto, ya que la inversión en maquinaria y en el sector agroindustrial es muy baja, y al compararlo con otros países como, por ejemplo, Estados Unidos, el valor del producto es la tercera parte de lo que vale en Colombia.

Por esta razón, para la arrocera Gélvez no es viable la exportación de arroz, puesto que los líderes del mercado son las empresas vinculadas al sector agroindustrial y que son fuertes en la región nortesantandereana. Por ello la empresa siempre está analizando las estrategias de las empresas líderes para su posible aplicación en su compañía para incrementar sus ventas y mantener su marca en el mercado, es decir, la mencionada arrocera no se enfoca en hacer estudios propios de mercadeo, y como se ha mencionado anteriormente, son reconocidos internamente factores que le han permitido perdurar en el tiempo. Adicionalmente, el análisis de la categoría deductiva de calidad y productividad se hace considerando la Figura 6.

Hace referencia a los recursos humanos, financieros, materiales y técnicos para obtener de primera mano y de la mejor calidad la materia prima, otorgando al agricultor préstamos financieros, capacitaciones para el buen manejo de los suelos, y semillas para la obtención de una materia prima que cumpla con los pará- 
Gerencia de las organizaciones.

Un enfoque empresarial

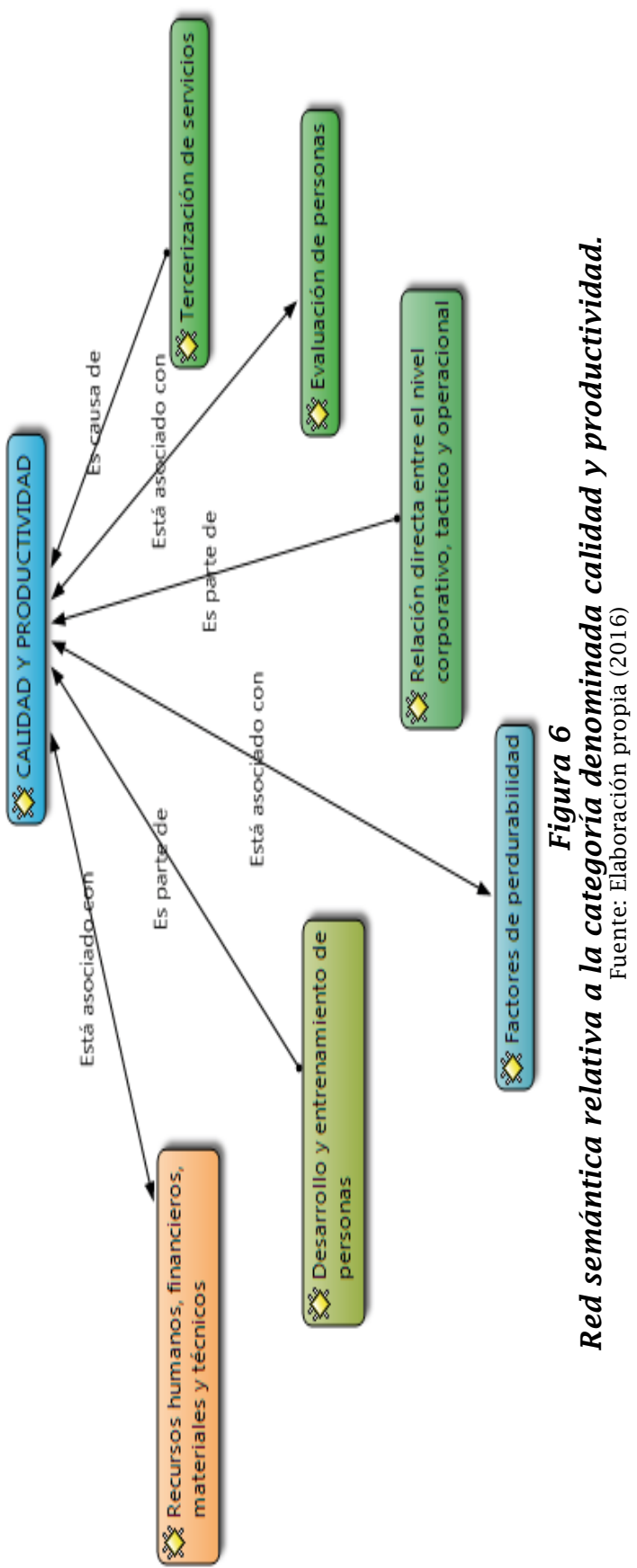


metros de calidad. Además, algunas tendencias empresariales de la actualidad se basan en la contratación o tercerización de servicios, procesos que no son ajenos a la arrocera Gélvez. Se pudo detectar que en las épocas donde se incrementa la demanda, es tercerizado el servicio de empaque con el objetivo de buscar mejores prácticas, bajo la modalidad de aliados, que permitan la optimización en recursos así como la agilidad en los procesos, manteniendo la calidad en sus productos.

Como se mencionó anteriormente, otro aspecto relevante en arrocera Gélvez es la comunicación que se maneja en los niveles de la jerarquización, existiendo la conexión entre los niveles corporativo, tácticos y operativos. En este sentido, se puede visualizar la comunicación como un factor recurrente en la organización, ya que es mencionado tanto en la gestión administrativa como en la categoría de calidad y productividad.

\section{Modelo de negocio Arrocera Gélvez S.A.S Modelo Canvas}

Para buscar el modelo de negocio de la organización Arrocera Gélvez se tomó el modelo Canvas de Osterwalder (2004, p.15), el cual establece que: "Un modelo de negocio es una herramienta conceptual que, mediante un conjunto de elementos y sus relaciones, permite expresar la lógica mediante la cual una compañía intenta ganar dinero generando y ofreciendo valor a uno o varios segmentos de clientes, la arquitectura de la firma, su red de aliados para crear, mercadear y entregar este valor, y el capital relacional para generar fuentes de ingresos rentables y sostenibles". Este lienzo permitió identificar, por medio de nueve bloques, todos aquellos aspectos que han hecho parte y participado en la creación de valor de la empresa, y así lograr crecimiento y perdurabilidad a través del tiempo. A continuación, en la Figura 7, el modelo Canvas construido con el análisis de la red semántica. 
Gerencia de las organizaciones.

Un enfoque empresarial

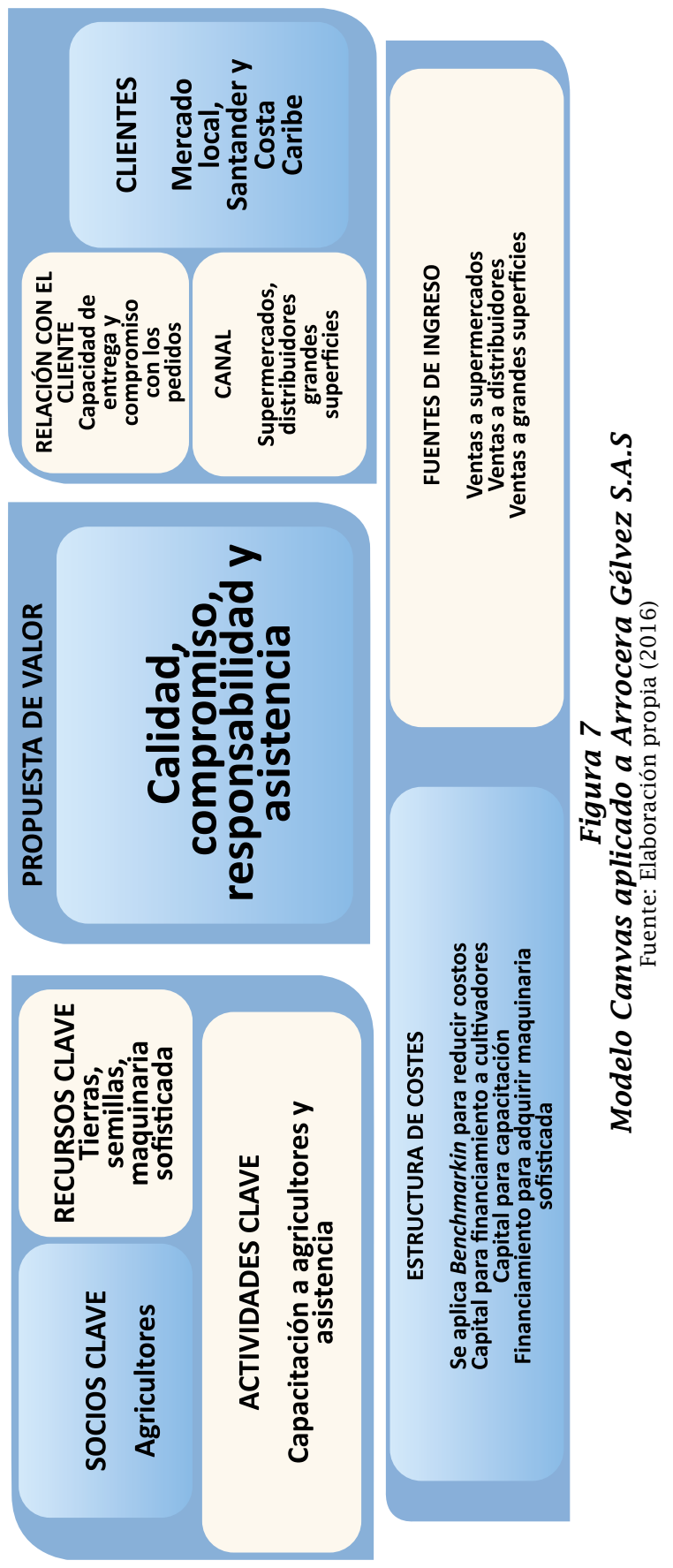




\section{Aspectos financieros en Arrocera Gélvez S.A.S}

El análisis documental se realizó con base en las publicaciones de las cien mejores empresas del Norte de Santander del Observatorio Económico de la Cámara de Comercio de Cúcuta, que refleja el comportamiento económico de estas importantes empresas en el departamento. La información recolectada corresponde a la base de datos de la Cámara de Comercio de Cúcuta, la Superintendencia de Sociedades y Supersubsidios, según indicadores y variables financieras. Tal información indica cómo actuaron las empresas según sus índices bajo un contexto de crecimiento nacional soportado por el PIB de cada año de estudio.

El análisis refleja que en el año 2015 hubo un comportamiento positivo en dos variables, ingresos y pasivo con $15,1 \%$ y $4 \%$ respectivamente, y negativo en tres, estos últimos ocasionados, según el CEO, por el cierre de la frontera ocurrido en agosto de ese año. Sin embargo, se mantiene dentro del ranking, y según la entrevista en la que participó el directivo, las relaciones comerciales con Venezuela se han reactivado por el desabastecimiento y casi nula producción que hay en ese país, permitiendo reactivar la venta de los productos de la línea económica Kogui y don Theo. Esto puede ocasionar, probablemente, que para el otro estudio del Observatorio estas variables muestran un desempeño positivo.

Las variables de ingreso y pasivo, sí reflejan un aumento positivo, generando confiabilidad en los bancos para endeudarse y clientes satisfechos con sus productos. Para el año 2014, la variable Ingresos tiene un significativo aumento respecto al 2013, con un $42,4 \%$ de aumento y el patrimonio con un $15,4 \%$. Además, se 
Gerencia de las organizaciones.

Un enfoque empresarial

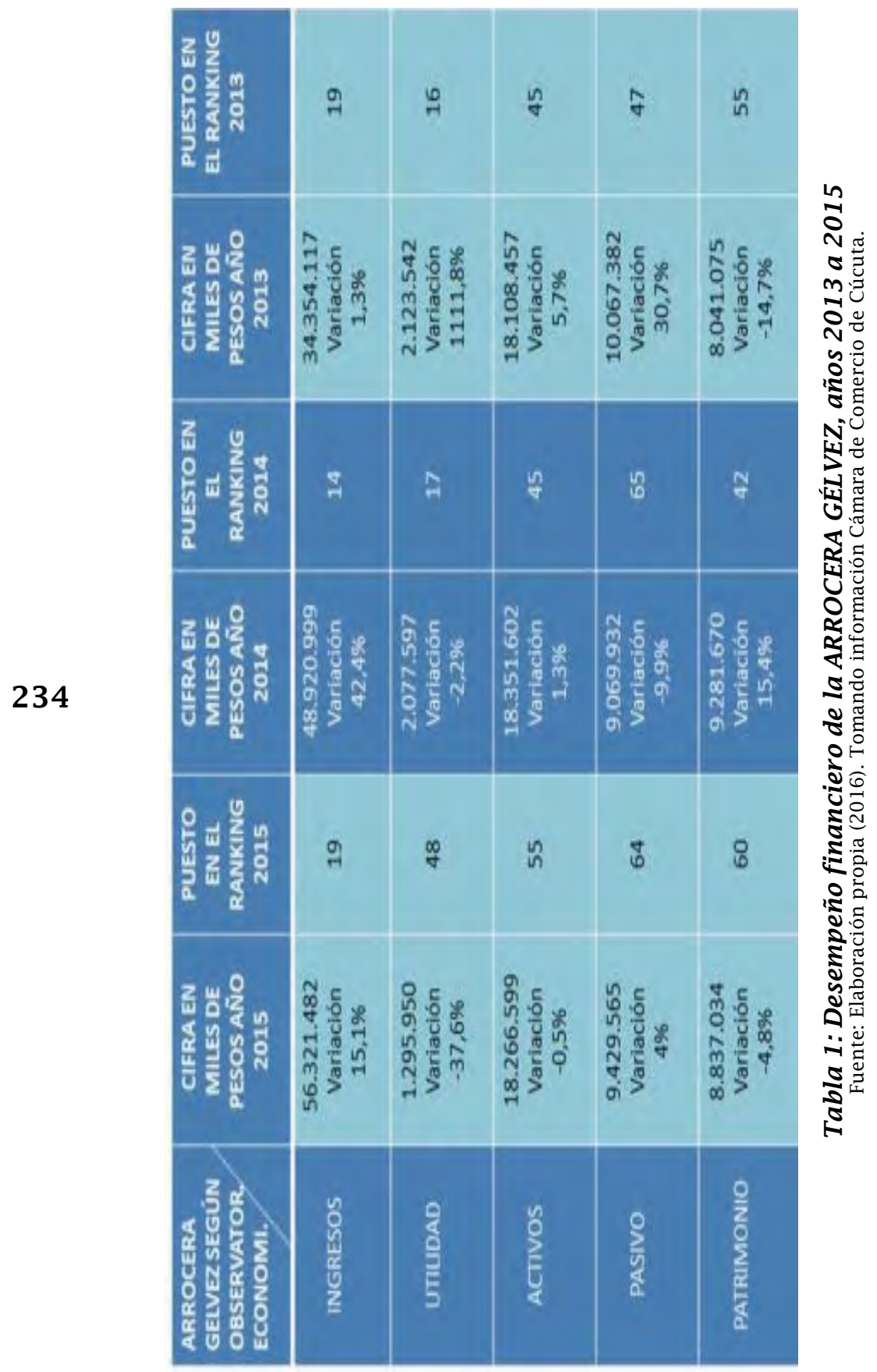


produjo también un aumento importante en comparación con el año inmediatamente anterior, reflejando su buena participación en el mercado, gracias a que en ese año se duplicó la producción del cereal debido a la demanda interna que ocasionó el fuerte control al contrabando, el cual le permitió también que gozara de un incremento en sus activos. El pasivo disminuyó y sus utilidades también; sin embargo, se mantuvieron considerablemente cerca a los resultados del año inmediatamente anterior.

En el 2013, sus cifras fueron todas positivas, excepto para el patrimonio con una disminución de $14,7 \%$, ocasionado por el considerable aumento en el pasivo. Sus utilidades se incrementaron de forma cuantiosa, demostrando que la organización y sus directivos han implementado estrategias oportunas para seguir invirtiendo y creciendo en el mercado.

En general se pudo analizar que la organización ha mantenido cifras muy parejas y ha procurado con esmero realizar las cosas bien para crecer y autosostenerse. Ha planificado muy bien su endeudamiento. Se observa que de los tres años de estudio, en el 2014 disminuyeron sus deudas y para el 2015 se incrementó sin mucha alarma. Desde las variables de beneficios e ingresos, esta última ha llevado un crecimiento constante en los tres años, que no reflejó cifras negativas en su variación respecto a cada año anterior, demostrando que su modelo de negocio ha mantenido desde años atrás un constante aprendizaje en todos sus procesos y siendo responsable cuando le ha tocado perder y afrontar los declives para poder responderle a sus clientes, esperando recuperarse rápidamente y así conseguir óptimos resultados en un nuevo intento. De esta manera lo hizo ver, reflejar y analizar 


\section{Gerencia de las organizaciones.}

Un enfoque empresarial

a través de las publicaciones que el Observatorio Económico difunde para el público en general.

A partir de los hallazgos encontrados en el presente proyecto, después de aplicarse la entrevista al Director Ejecutivo (CEO) de la organización arrocera Gélvez S.A.S, se demuestra que existen factores relevantes que permiten que una empresa familiar perdure en el tiempo. A continuación se mencionan los hallazgos obtenidos comparados con la teoría:

En cuanto a innovación, estos resultados guardan cierta relación con lo que sostiene el Manual de innovación para pymes (2013), donde, refiriendose a un producto o servicio como la define "una de las estrategias más habituales para ganar competitividad en el mercado, mediante la reducción de costes de producción o

236 distribución" (p.8). En los resultados obtenidos para la Arrocera Gélvez, se logra analizar el aspecto de innovación, entendido desde el Manual de innovación para pymes (2013), "como un nuevo bien o servicio o uno sensiblemente mejorado respecto a sus características básicas, especificaciones técnicas y otros componentes intangibles, finalidades deseadas o prestaciones" (p.8), en torno al cual se concluye que no existe innovación de productos.

La referida arrocera está enfocada, solamente, en mantener la marca y no en el lanzamiento de nuevos productos o mejoramiento de los productos ya existentes, respecto a la innovación tecnológica considerada desde el Manual de innovación para pymes (2013) como "la propia tecnología la que sirve como medio para introducir un cambio en la empresa, mediante la aplicación industrial del conocimiento científico o tecnológico" (p.7). 
En torno a este tipo de innovación, en los últimos años la empresa en estudio ha innovado en la adquisición de maquinaria o herramientas tecnológicas japonesas, lo que le ha permitido agilizar sus procesos, que el Manual de innovación para pymes (2013) destaca como "redefinición de los procesos productivos o en la aplicación de una tecnología de producción nueva o sensiblemente mejorada, con el fin de aumentar el valor del producto final" (p.8). En cuanto a la producción, se apunta a una optimización de los costes y/o tiempos de fabricación, obteniendo mejoras en la productividad y mejores tiempos de respuesta al cliente, por lo tanto, no existe innovación comercial, pues esta empresa no le apuesta a los nuevos procesos de marketing, porque no cree necesario realizar cierta inversión para conocer de primera mano las necesidades del cliente y lograr aumentar sus ventas. Como se mencionó anteriormente, solo está enfocada en mantener su marca. Dicho estudio no concuerda con la teoría planteada según el Manual de innovación para pymes (2013) que propone que este tipo de innovación se da en "la variación de cualquiera de las variables de marketing que influyen en el lanzamiento de un nuevo producto o servicio" (p.8), solo se está innovando en ciertos procesos, lo que no permite fomentar paralelamente la innovación en la empresa.

En lo referente a la gestión administrativa, se hace mención a la consecución de objetivos y metas propuestas por la organización mediante un proceso administrativo definido en planear, organizar, dirigir y controlar. Según Chiavenato (2002), "la planeación define lo que pretende realizar la organización en el futuro y cómo debe realizarlo" (p.17), y muy claramente se puede visualizar en la visión de Arrocera Gélvez, definida como "Arrocera Gél- 


\section{Gerencia de las organizaciones.}

Un enfoque empresarial

vez S.A.S. en el año 2020 será la más prestigiosa y posicionada organización del norte y oriente colombiano en la producción y comercialización de arroz, productos a base de arroz, derivados y subproductos". Arroz Gelvez (2016) maneja la organización de la mejor manera para alcanzar el logro de sus objetivos, donde el CEO de la organización delega autoridad sobre otras personas para realizar el proceso de la mejor manera posible y obtener calidad en sus productos.

Según Chiavenato (2002), la organización se define como "la función administrativa relacionada con la asignación de tareas, la distribución de tareas a los equipos o departamentos y la asignación de los recursos necesarios a los equipos o departamentos" (p.17). Es por eso que la adquisición de nuevas herramientas tecnológicas ha permitido agilizar los procesos para obtener mayor volumen en producción y calidad en sus productos.

Continuando en la tercera etapa del proceso administrativo, se hace necesaria la dirección, que según Chiavenato (2002), "se encarga de comunicar las tareas e influenciar y motivar a las personas para que ejecuten las tareas esenciales" (p.18). Considerada como una de sus mejores estrategias para obtener mejor productividad, el CEO de la organización implementa planes motivacionales para que sus empleados se sientan a gusto y realicen sus funciones cumpliendo a cabalidad con lo necesario para permanecer en el mercado, obteniendo de primera mano la información necesaria, pues existe una fuerte comunicación entre los niveles jerárquicos de Arrocera Gélvez. Finalizando con el proceso administrativo, (Chiavenato, 2002), el control "representa el acompañamiento, monitoreo y evaluación de desempeño organi- 
zacional para verificar si las tareas se ejecutan de acuerdo con lo planeado, organizado y dirigido" (p.18), donde constantemente se está realizando un monitoreo para identificar puntos fuertes y mejorar puntos débiles en la organización.

Para ello, de manera continua el CEO visita cada una de las áreas administrativas y de producción para verificar el cumplimiento de lo propuesto por la empresa. Estas acciones se hacen sin tener que esperar cierto tiempo para realizar evaluaciones, promoviendo así un mejoramiento continuo.

Por otro lado, en la Arrocera Gélvez se puede determinar que no existe una alta relación entre lo mencionado por Kotler (2006), sobre la segmentación de mercados delimitados en segmentos geográficos, demográficos y psicográficos contra los hallazgos obtenidos en arrocera Gélvez. En este sentido, se considera la caracterización de la segmentación geográfica establecida (Chiavenato, 2006), cuando expresa que la segmentación de mercados "se caracteriza por dividir el mercado en unidades geográficas diferentes, tales como naciones, estados, regiones, condados, ciudades o barrios" (p.260); es acá donde se puede hacer relación, ya que Arrocera Gélvez, geográficamente está segmentada en los departamentos de los Santanderes, así como también en los departamentos de la Costa (que desde sus inicios siempre han sido su mercado objetivo).

Además, según Kotler (2006), la segmentación demográfica "consiste en dividir el mercado en distintos grupos, según variables como la edad, el tamaño del núcleo familiar, el ciclo de vida familiar, el sexo, los ingresos, la profesión, la educación, la religión, 


\section{Gerencia de las organizaciones.}

Un enfoque empresarial

la raza, la generación, la nacionalidad y la clase social" (p.260). No existe vinculación con lo obtenido, dado que en la organización no se cuenta con grupos según variables para ofrecer el producto, sin importar la edad, el estrato socioeconómico, el género, entre otros. Cualquier persona puede adquirir los productos o derivados de Arrocera Gélvez, respecto a la segmentación psicográfica mencionada por este autor como "la psicografía es la ciencia de utilizar factores psicológicos y demográficos conjuntamente para entender mejor a los consumidores" (p.264). Se analiza que no existe asociación con el teórico mencionado, debido a que actualmente no se realizan estudios de mercadeo para conocer los gustos y preferencias del cliente, pues lo que se busca es mantener la marca y para eso principalmente Arrocera Gélvez se enfoca en realizar benchmarking.

En lo referente a competitividad, cruzando los resultados encontrados en la presente investigación con la teoría de las tres estrategias genéricas de Porter (2009), dadas por liderazgo global en costos, diferenciación y enfoque o concentración, no existe mayor correlación entre los dos puntos de vista, desde el autor y CEO de la organización. El liderazgo en costos globales, según Porter (2009), "exige la construcción agresiva de instalaciones de escala eficiente, la búsqueda vigorosa de reducción de costos a partir de la experiencia, un control riguroso de gastos variables y fijos" (p.52), lo que indica que en arrocera Gélvez S.A.S. se realiza el manejo y adquisición de nuevas herramientas tecnológicas con el fin de reducir y manejar costos inferiores a los de la competencia en el sector industrial, a medida que el volumen de producción aumente, ofreciendo así varias líneas de productos denominados como "línea económica". Esto permite clasi- 
ficar productos de menor precio y con mejor poder de adquisición para los consumidores, manteniendo la calidad en cada uno de sus productos ofertados a muchos segmentos del sector de la Costa y los Santanderes que es definido como su mercado natural.

En palabras de Porter (2009), la diferenciación "brinda protección en contra de la rivalidad porque los clientes son leales a la marca y porque disminuye la sensibilidad al precio" (p.54). No existe relación entre la estrategia de Porter y la aplicada por el CEO de la Arrocera Gélvez S.A.S., debido a que para el CEO de la organización lo que lo hace diferente es el compromiso con sus proveedores, es decir, con los agricultores que son considerados como sus aliados principales, ya que son quienes le proveen la materia prima, de primera mano, para lograr ofrecer calidad a sus clientes. Pasando ya a la última estrategia, establecida por Porter (2009), se hace referencia al enfoque o concentración, la cual permite que la empresa "se centre en un grupo de compradores, en un segmento de la línea de productos o en un mercado geográfico" (p.55).

Esta situación no es acorde con los hallazgos del presente estudio, pues en Arrocera Gélvez, no le apuestan a realizar estudios de mercadeo para explorar en nuevos mercados. Por consiguiente, no consideran tener que realizar una inversión que le traerá costos muy altos para tan poca utilidad, sino que actualmente, solo se enfocan en realizar benchmarking. Cada estrategia genérica es un enfoque básicamente distinto para crear y mantener una ventaja competitiva. Es por eso que una empresa siempre debe buscar y aprovechar todas las oportunidades de reducción 


\section{Gerencia de las organizaciones.}

Un enfoque empresarial

de costos que se puedan presentar en el mercado, siempre y cuando no sacrifiquen la diferenciación.

Se continúa con la calidad y productividad en Arrocera Gélvez S.A.S., desde el enfoque teórico. Chiavenato (2002), define la calidad como "capacidad de atender durante todo el tiempo las necesidades del cliente" (p.683). En la presente investigación se encuentra coherencia, ya que en Arrocera Gélvez S.A.S. se busca brindar al cliente lo que desee y se adapta a los recursos financieros con los que cuenta el consumidor final. Es por eso que nació la necesidad de crear la línea económica de arroz, como lo es el arroz Don Theo y arroz Kogui, brindando al consumidor final satisfacción y gusto al poder obtener dichos productos. En este sentido, una de las estrategias del CEO de la organización es brindar al agricultor recursos necesarios para obtener la materia prima de primera mano y de la mejor calidad, otorgando al agricultor préstamos financieros, capacitaciones para el buen manejo de los suelos, y semillas para la obtención de una materia prima que cumpla con los parámetros de calidad.

En el proceso para obtener un producto final existe la motivación hacia el personal operario y administrativo. Chiavenato (2002) la define como "Deseo de dedicar gran esfuerzo a los objetivos organizacionales, condicionado por la capacidad del esfuerzo para satisfacer alguna necesidad individual" (p.632), donde se confirma que para que un empleado se sienta motivado debe existir una interacción entre el individuo y la situación que se esté viviendo en el momento. El resultado obtenido en la presente investigación se marca de una manera positiva, ya que en Arrocera Gélvez S.A.S., se cuenta con planes motivacionales e imple- 
mentación de estrategias que permiten al colaborador sentirse a gusto de pertenecer a la empresa; así mismo se ofrecen capacitaciones porque como lo afirma el CEO de Arrocera Gélvez S.A.S.," Es importante que la gente esté aprendiendo". De esta manera se logra una mayor productividad a través de la eficiencia y eficacia que es definida por Chiavenato (2002), "eficacia significa alcanzar objetivos y resultados. Un trabajo eficaz es aquel que resulta provechoso" (p.31) y, "eficiencia significa hacer las cosas bien y de manera correcta" (p.31). Se puede concluir que si la empresa cuenta con personal motivado mediante reconocimientos, bonificaciones, incentivos, entre otros, donde no solo se beneficie el personal administrativo sino también sus familias, la organización obtendrá mayor beneficencia en cuanto a calidad y productividad, incrementándose de forma positiva el bienestar de la Arrocera Gélvez y de cada uno de sus colaboradores.

Buscar y querer perdurar en el tiempo requiere implementar una serie de aspectos y factores, tanto personales como grupales, que se determinan gracias a algunos autores que han enfatizado en ciertas categorías administrativas y del entorno en donde se desenvuelve y opera una empresa. Este estudio también permitió conocer cuáles de esos referentes teóricos son los que más se aplican, y cuáles son propios y fueron hallados en lo particular. Así mismo se analizó y se comprendió que no necesariamente las personas dueñas de empresas o emprendedores, deben poseer todo el conocimiento de inmediato que les permita poder poner en marcha su iniciativa de negocio. Se observó que la organización Arrocera Gélvez ha estado en un aprendizaje y mejoramiento continuo que le ha permitido reponerse de errores y yerros, que por las circunstancias del entorno fronterizo y malas decisiones, la han llevado a resbalar y tropezar. 


\section{Gerencia de las organizaciones.}

Un enfoque empresarial

Se concluye que las empresas que busquen una autosotenibilidad se deben apoyar, y basarse en teorías administrativas que ya han sido aplicadas y analizadas por expertos, pero también a este gran conocimiento; se debe tener la valentía de querer afrontar retos que requieran innovación y deseo de instruirse, no importando la longevidad a que se llegue, porque las competencias son lo que se traspasa a las siguientes generaciones. Finalmente, se identificaron factores de perdurabilidad que le han permitido a Arrocera Gélvez permanecer por más de 50 años en el mercado, como son el compromiso con sus proveedores $y$ la calidad con sus clientes.

\section{REFERENCIAS BIBLIOGRÁFICAS}

Arroz Gélvez. (2016). Quiénes somos. Recuperado en: https:// www.arrozgelvez.com/home/quienes.php

Bonilla, E. y Rodríguez, P. (1997). Más allá del dilema de los métodos. La investigación en ciencias sociales. Santafé de Bogotá: Ediciones Uniandes.

Bracho, O., García, J. y Jiménez, E. (2012). Factores de liderazgo transformacional en contralorías municipales del Estado de Zulia. Revista Coeptum, 3(2), 127-140.

Cámara de Comercio de Cúcuta (s.f). Recuperado el 15 de noviembre de 2016, http://www.cccucuta.org.co/

Confecámaras (2016). Aumentó la creación de empresas en el país en el primer semestre del año, consultado el 10 de octubre de 2016, de http://www.confecamaras.org.co/noticias/4 62-17-aumento-la-creacion-de-empresasen-el-pais-en-el-primer-semestre-del-ano-2

Consejo Privado de Competitividad (2016). Índice Departamental de Competitividad 2016, consultado el 3 de octubre 
de 2016 de http://idc.compite.com.co/departamento/nor te-de-Santander

Chiavenato, I. (2002). Administración en los nuevos tiempos. Colombia: McGraw-Hill.

Daft, R. (2011). Teoría y diseño organizacional. México: Cengaje Learning.

DANE (2015). Cuentas Anuales Departamentales Colombia. Producto Interno Bruto, consultado el 3 de octubre de 2016, de https://www.dane.gov.co/files/investigacio nes/pib/departamentales/B_2005/Bol_dptal_2014pre.pdf

DANE (2016). Empleo Informal y Seguridad Social, consultado el 19 de septiembre de 2016 de http://www.dane.gov.co/index. php/estadisticas-por-tema/mercado-laboral/empleoinformal-y-seguridadsocial?phpMyAdmin=3 om 27vamm65hhkhrtgc8rrn2g 4

Datacúcuta (s.f.). Plan Regional de Competitividad del Norte de Santander, consultado el 20 de septiembre de 2016, de http:// www.datacucuta.com/PDF/publicaciones-externas/COMISIONREGIONALDECOMPETITIVIDAD/PLAN\%20REGIONAL\%2 ODE\%20COMPETITIVIDAD.pdf

Flint, P. (1999). Gestión de Empresas en crisis: técnicas de reflotamiento. Segunda Edición. Bogotá: Cámara de Comercio.

Gaitán Rozo, A., Hincapié Cardona, A. L., Castro Velasco, J. D. (2013). Estudio sobre Empresas colombianas perdurables, casos de éxito. Bogotá: Superintendencia de Sociedades.

García, J., Durán, S. y Prieto, R. (2017). Políticas de gestión de talento humano para el desarrollo de competéncias gerenciales en empresas metalmecánicas. Revista Face, 17(2).

García, J., Durán, S., Parra, M. y Marceles, V. (2017). Dirección estratégica del talento humano para el fomento de valores en los cuerpos policiales venezolanos. Revista Espacios, 38(32), 16-28. 


\section{Gerencia de las organizaciones.}

Un enfoque empresarial

Gómez, B. G (2016). 10 trampas familiares en las que incurren los empresarios. Revista Dinero.

Hernández Sampieri, R., Fernández Collado, C., Baptista Lucio, P. (2014). Metodología de la Investigación. Sexta Edición. México: McGraw-Hill.

Hurtado, J. (2010). Metodología de la investigación: Guía para la comprensión holística de la ciencia. Cuarta edición. Caracas: Quirón Ediciones.

Informe Nacional de competitividad (2016-2017). Consejo privado de competitividad. Colombia.

Kotler, P. (2006). Dirección de marketing. Madrid: Pearson.

Manual de innovación. Guía práctica de gestión de la i+D+i para pymes (2013). Centro Europeo de Empresas e Innovación. España.

Martínez, M. (2010). Ciencia y arte en la metodología cualitativa.

Segunda edición. México: Editorial Trillas.

Observatorio Económico de la Cámara de Comercio de Cúcuta (2014). Las 300 Empresas que hacen más próspero a Norte de Santander, consultado el 8 de noviembre de 2016, de: http://www.datacucuta.com/PDF/estudiossectoriales/1.EMPRESAS\%2 0MAS\%2 0REPRESENTATIVAS\%20DE\%2 0LA\%20RE GION/3\%20edicion\%20300\%20empresas.pdf

Observatorio Económico de la Cámara de Comercio de Cúcuta (2016). 100 Empresas que hacen más Próspero a Norte de Santander, consultado el 8 de noviembre de 2016 de: http:// www.datacucuta.com/images/100em presas2015.pdf

Observatorio Económico de la Cámara de Comercio de Cúcuta (2015). Las Mejores Empresas del Norte de Santander, consultado el 8 de noviembre de 2016, de: http://www.datacucuta.com/PDF/estudiossectoriales/1.EMPRESAS\%20MAS\%20 REPRESENTATIVAS\%20DE\%20LA\%20RE GION/4\%20edicion\%20 300\%20empresas.pdf 
Osterwalder, A. (2004). La Ontología del modelo de negocios: Una propuesta desde un enfoque de Ciencia y Diseño. Disertación doctoral. Lausana: Escuela de Altos Estudios Comerciales de la Universidad de Lausana, consultado el 3 de noviembre de 2016, de: http://www.hec.unil.ch/aosterwa/PhD/Oster walder_PhD_BM_Ontology.pdf

Plan Regional de Competitividad de Norte de Santander (2021). Observatorio Económico de la Camara de Comercio de Cúcuta. Porter, M. E. (2009). Estrategia Competitiva; Técnicas para el análisis de los sectores industriales y de la competencia. México: Grupo Editorial Patria.

Poza, E. (2013). Empresas familiares. España: Cengaje Learning. Restrepo, L., Vélez, A., Méndez, C., Rivera, H. y Mendoza, L. (2009). Aproximación una metodología para la identificación de componentes que crean condiciones para la perdurabilidad en empresas colombianas. Bogotá: Universidad del Rosario.

Secretaría de Hacienda de San José de Cúcuta (s.f). Recuperado el 15 de noviembre de 2016, http://haciendaalcaldiadecucuta. gov.co/impuestoscucuta/

Stake, R. (1999). Investigación con Estudio de Casos. Segunda edición. Madrid: Ediciones Morata.

Strauss, A., Corbin, J. (2002). Bases de la investigación cualitativa. Técnicas y procedimientos para desarrollar la teoría fundamentada. Primera edición. Medellín: Editorial Universidad de Antioquia.

\footnotetext{
Cómo citar este capítulo:
}

Nava-Sarmiento, E., Jaimes-Mora, S. y Barrera-Rodríguez, L. (2017). Factores que inciden en la perdurabilidad de una empresa familiar del sector agroindustrial. En Prieto-Pulido, R. y García-Guiliany, J. (2017). Gerencia de las organizaciones. Un enfoque empresarial. Ediciones Universidad Simón Bolívar. Barranquilla-Colombia. 205-247. 